\title{
WIELKOŚĆ DOTACJI NA DZIAŁALNOŚĆ STATUTOWA A EFEKTYWNOŚĆ NAUKOWA WYDZIAŁÓW SZKOŁY GŁÓWNEJ GOSPODARSTWA WIEJSKIEGO W WARSZAWIE
}

Piotr Grzegorz Pietrzak

Katedra Ekonomiki i Organizacji Przedsiębiorstw

Szkoła Główna Gospodarstwa Wiejskiego w Warszawie

\begin{abstract}
Abstrakt. Zarówno w Polsce, jak i w pozostałych krajach Unii Europejskiej szkoły wyższe finansowane są przede wszystkim z funduszy publicznych. Wielkość środków przeznaczonych na ten cel wynika z wartości i ze znaczenia, jakie społeczeństwa wiążą z upowszechnianiem kształcenia na poziomie wyższym. Coraz większe znaczenie w określaniu poziomu dotacji odgrywają jednak wskaźniki efektywności. Tym samym punktem wyjścia przy projektowaniu procedur alokacji środków publicznych jest postulat, aby do jednostek bardziej efektywnych trafiało więcej środków niż do jednostek mniej efektywnych. Hipoteza badawcza opracowania zakłada, że istnieje silna, pozytywna korelacja między wielkością dotacji na działalność statutową a efektywnością naukową wydziałów Szkoły Głównej Gospodarstwa Wiejskiego w Warszawie.
\end{abstract}

Słowa kluczowe: finanse publiczne, dotacja statutowa, efektywność naukowa, wskaźniki złożone

\section{WSTĘP}

Edukacja wyższa stanowi przykład dobra merytorycznego (społecznie pożądanego) tj. dobra, „które jest na tyle ważne, że gdy jego konsumpcja na wolnym rynku jest na niewystarczającym poziomie, władze interweniują w celu jej zwiększenia, nawet wbrew preferencjom konsumentów" [Musgrave 1987]. Wynika to przede wszystkim z faktu, że społeczne korzyści krańcowe z konsumpcji dóbr meryto- 
rycznych (rozumiane jako suma korzyści dla konsumenta i pozostałych członków społeczeństwa) są wyższe od indywidualnych korzyści krańcowych [Mendoza 2011]. Jest to wywołane pojawieniem się korzystnego konsumpcyjnego efektu zewnętrznego [Kamerschen i in. 1991].

W przypadku edukacji wyższej pozytywne efekty zewnętrzne posiadają dwojaki charakter. Po pierwsze, przynosi ona korzyści gospodarcze (podnosząc wydajność pracowników, jak również umożliwiając im zwiększenie wydajności innych). Po drugie, wykształcenie wyższe generuje ogólniejsze korzyści społeczne, niewątpliwie trudne do zmierzenia w kategoriach finansowych [Wilkin 2009]. Edukacja wyższa przyczynia się do umocnienia demokracji i praw człowieka, poprawy wskaźników zdrowotnych [McMahon 2002] czy redukcji przestępczości [Lochner i Moretti 2004].

Szkoły wyższe są odpowiedzialne nie tylko za tworzenie kapitału ludzkiego, ale również za „produkcję” wiedzy. Zarówno tej, która jest łatwo aplikowana (badania stosowane), jak i tej będącej w sferze teorii (badania podstawowe). Prowadzone na uczelniach badania naukowe w dużym stopniu wpływają na rozwój innowacji w różnych branżach oraz stanowią ważną podstawę patentów przemysłowych [Breschi i in. 2007].

Tak ogromne znaczenie edukacji dla jednostki i społeczeństwa powoduje, że państwa wspierają finansowo działalność szkół wyższych. Nie oznacza to jednak, że $\mathrm{w}$ dystrybucji środków publicznych nie można wykorzystać proefektywnościowo czy prorynkowo zorientowanych mechanizmów i instrumentów [Fiedor 2015]. Dotyczy to zarówno działalności dydaktycznej, jak i naukowej. Na przykład na Litwie, Węgrzech oraz w Rumunii efektywność uczelni uwzględnia się przy obliczaniu od 12 do $20 \%$ dotacji blokowej na działalność dydaktyczną i operacyjną oraz badania [Komisja Europejska 2009]. W Polsce w trwających pracach nad projektem Ustawy 2.0 wskazuje się na konieczność zwiększenia roli kryteriów proefektywnościowych w podziale środków publicznych. Z tego powodu celem artykułu uczyniono próbę określenia związku między poziomem dotacji na działalność statutową a efektywnością naukową 13 wydziałów Szkoły Głównej Gospodarstwa Wiejskiego w Warszawie. Hipoteza badawcza opracowania zakłada, że istnieje silna ${ }^{1}$, pozytywna korelacja między wielkością dotacji statutowej w przeliczeniu na nauczyciela akademickiego a efektywnością naukową wydziałów (obliczoną na podstawie wskaźnika złożonego) SGGW.

${ }^{1}$ Przyjęto następującą klasyfikację [Guilford 1956]: $|\mathrm{r}|=0$ - brak korelacji, $0,0<|\mathrm{r}| \leq 0,2$ - korelacja słaba, $0,2<|\mathrm{r}| \leq 0,4$ - korelacja mała, $0,4<|\mathrm{r}| \leq 0,7$ - korelacja umiarkowana, $0,7<|\mathrm{r}| \leq 0,9$ - korelacja silna, $0,9<|\mathrm{r}|<1,0$ - korelacja bardzo silna, $|\mathrm{r}|=1$ - korelacja pełna. 


\section{WYDATKI PUBLICZNE NA SZKOLNICTWO WYŻSZE W POLSCE}

Głównym źródłem finansowania uczelni publicznych w Polsce są dotacje państwowe, co dotyczy zarówno działalności dydaktycznej (dotacja algorytmiczna), jak i badawczej (dotacja statutowa). W roku akademickim 2014/2015 wydatki publiczne na szkolnictwo wyższe wynosiły ponad 14 mld PLN i kształtowały się na poziomie 0,71\% PKB (tabela 1). Ze względu, że w dalszej części opracowania autor będzie odnosił się wyłącznie do dotacji na działalność statutową (ze względu na brak danych dotyczących dotacji algorytmicznej), podjęta dyskusja będzie dotyczyła wyłącznie tej formy finansowania.

TABELA 1. Wydatki publiczne na szkolnictwo wyższe w Polsce w latach 1995-2014

\begin{tabular}{|c|c|c|c|c|c|}
\hline \multirow[b]{2}{*}{ Lata } & \multicolumn{2}{|c|}{ Wydatki (mln PLN) } & \multicolumn{2}{|c|}{$\begin{array}{c}\text { Wskaźnik dynamiki zmian } \\
\text { wydatków budżetowych }\end{array}$} & \multirow{2}{*}{$\begin{array}{c}\text { Udział } \\
\text { wydatków } \\
\text { publicznych } \\
\text { w PKB (\%) }\end{array}$} \\
\hline & $\begin{array}{l}\text { z budżetu } \\
\text { państwa }\end{array}$ & $\begin{array}{c}\text { z budżetów } \\
\text { jednostek } \\
\text { samorządu } \\
\text { terytorialnego }\end{array}$ & nominalny & realny & \\
\hline 1995 & 2174,7 & 2,8 & - & - & 0,65 \\
\hline 1996 & 3002,4 & 8,9 & 138,1 & 115,1 & 0,71 \\
\hline 1997 & 3752,2 & 11,4 & 125,0 & 108,8 & 0,73 \\
\hline 1998 & 4272,3 & 10,7 & 113,9 & 101,8 & 0,71 \\
\hline 1999 & 5070,5 & 14,2 & 118,7 & 110,6 & 0,76 \\
\hline 2000 & 5326,7 & 20,4 & 105,1 & 95,4 & 0,72 \\
\hline 2001 & 6370,7 & 32,6 & 119,6 & 113,4 & 0,82 \\
\hline 2002 & 6829,6 & 38,6 & 107,2 & 105,2 & 0,85 \\
\hline 2003 & 7049,2 & 28,2 & 103,2 & 102,4 & 0,84 \\
\hline 2004 & 8822,3 & 31,9 & 125,2 & 120,9 & 0,96 \\
\hline 2005 & 9676,5 & 76,8 & 109,7 & 107,4 & 0,99 \\
\hline 2006 & $9888,7^{*}$ & 122,0 & 102,2 & 101,2 & 0,94 \\
\hline 2007 & 10701,4 & 143,5 & 108,2 & 105,6 & 0,93 \\
\hline 2008 & 11091,0 & 100,0 & 103,6 & 99,5 & 0,88 \\
\hline 2009 & 11654,5 & 197,0 & 105,1 & 101,5 & 0,88 \\
\hline 2010 & 11722,4 & 70,2 & 100,6 & 98,0 & 0,71 \\
\hline 2011 & 12009,2 & 72,8 & 102,4 & 98,2 & 0,67 \\
\hline 2012 & 12402,1 & 74,7 & 103,3 & 99,6 & 0,65 \\
\hline 2013 & 13203,4 & 82,4 & 106,5 & 105,5 & 0,68 \\
\hline 2014 & 14389,7 & 87,5 & 109,0 & 109,0 & 0,71 \\
\hline
\end{tabular}

* Dane od 2006 roku pomniejszone o wydatki niewygasające oraz dotacje dla jednostek samorządu terytorialnego.

Źródło: Opracowanie własne na podstawie „Szkoły wyższe i ich finanse 2001-2015”. 
Dotacja statutowa ma charakter instytucjonalny. Jej dysponentami są dziekani, a nie rektorzy czy administracja centralna [Majewska 2015]. Składają się na nią:

- dotacja podmiotowa na utrzymanie potencjału badawczego - tzw. BST,

- finanse na badania służące rozwojowi młodych naukowców oraz uczestników studiów doktoranckich - tzw. DSM,

- $\quad$ program na utrzymanie specjalnych urządzeń badawczych - tzw. SPUB.

Od 1 stycznia 2015 roku obowiązują nowe zasady i nowy tryb przyznawania oraz rozliczania środków służących finansowaniu działalności statutowej. W obecnym systemie podstawowym kryterium ustalania wielkości dotacji stała się kategoria naukowa, obrazująca potencjał jednostki i efekty prowadzonych przez nią badań. Innymi słowy na największą premię finansową od 2015 roku mogą liczyć elitarne jednostki badawcze z kategorią „A+”. Tym samym wprowadzone zmiany w większym stopniu uzależniły wielkość przyznawanej dotacji statutowej od wyników osiąganych przez szkoły wyższe w zakresie działalności badawczo-naukowej. Ocena parametryczna uwzględnia bowiem w swoich kryteriach m.in.: liczbę zdobytych patentów, praw ochronnych na wzory użytkowe i znaki czy liczbę publikacji w czasopismach naukowych mających współczynnik wpływu - IF (ang. impact factor) wymienionych w części A wykazu Ministerstwa Nauki i Szkolnictwa Wyższego (MNiSW). Finansowanie zorientowane głównie na osiągnięcia szkół wyższych w zakresie efektywności naukowo-badawczej jest zgodne z podejściem określanym w literaturze anglojęzycznej jako performancebased funding [Kaikkonen 2016].

\section{METODY BADAŃ}

W niniejszym opracowaniu dokonano celowego doboru obiektu - Szkoły Głównej Gospodarstwa Wiejskiego w Warszawie. W odniesieniu do SGGW badania mają charakter pełny i dotyczą 13 wydziałów wyodrębnionych w jej strukturze, a mianowicie: Rolnictwa i Biologii (WRiB), Medycyny Weterynaryjnej (WMW), Leśnego (WL), Ogrodnictwa, Biotechnologii i Architektury Krajobrazu (WOBiAK), Budownictwa i Inżynierii Środowiska (WBiIŚ), Technologii Drewna (WTD), Nauk o Zwierzętach (WNoZ), Nauk o Żywności (WNoŻ), Nauk o Żywieniu Człowieka i Konsumpcji (WNoŻCziK), Inżynierii Produkcji (WIP), Nauk Ekonomicznych (WNE), Nauk Społecznych (WNS), Zastosowań Informatyki i Matematyki (WZIiM). W analizie efektywności naukowej wydziałów wykorzystano materiały wewnętrzne SGGW pochodzące ze sprawozdania rektora z działalności uczelni za rok akademicki 2015/2016.

W pomiarze efektywności naukowej wydziałów wykorzystano metodę wskaźników złożonych - CI (ang. composite indicators), która ma zastosowanie zarów- 
no w wymiarze kształtowania polityk, jak i w podejmowaniu decyzji o znaczeniu operacyjnym [Szuwarzyński i Julkowski 2014]. Wskaźniki złożone posłużyły m.in. do oceny efektywności hiszpańskiego systemu edukacji [Murias i in. 2008].

Na potrzeby badania przyjęto wyjściowy zestaw trzech wskaźników cząstkowych ${ }^{2}$, które posłużyły do konstrukcji wskaźnika złożonego:

- liczbę punktów za publikacje w przeliczeniu na nauczyciela akademickiego $\left[I_{1}\right]$,

- liczbę projektów NCN w przeliczeniu na nauczyciela akademickiego $\left[I_{2}\right]$,

- liczbę nagród rektorskich za osiągnięcia naukowe w przeliczeniu na nauczyciela akademickiego $\left[I_{3}\right]$.

Budowa wskaźnika złożonego wymagała doprowadzenia wskaźników cząstkowych do wzajemnej porównywalności. Z analizy literatury przedmiotu wynika, że najlepsze właściwości formalne wśród metod normalizacji ma unitaryzacja zerowana [Kukuła 2012]. Ze względu na to, że wszystkie wskaźniki cząstkowe były stymulantami (im większa wartość, tym lepiej), wzór na ich unitaryzację przybrał następującą postać [Kukuła 2012]:

$$
I_{i_{-} \text {norm }}=\frac{I_{i}-\min \left\{I_{i}\right\}}{\max \left\{I_{i}\right\}-\min \left\{I_{i}\right\}}
$$

gdzie:

$I_{i \text { norm }}$ - znormalizowana wartość $i$-tego wskaźnika cząstkowego,

$I_{i} \quad$ - wartość $i$-tego wskaźnika cząstkowego,

$\max \left\{I_{i}\right\}$ - wartość maksymalna wskaźnika cząstkowego,

$\min \left\{I_{i}\right\}$ - wartość minimalna wskaźnika cząstkowego.

Wartość zagregowanego wskaźnika dla każdego wydziału jest sumą ważoną znormalizowanych wskaźników cząstkowych [OECD 2008]:

$$
\begin{gathered}
C I_{r}=\sum_{q=1}^{Q} w_{q} I_{q r} \\
\sum_{q} w q=1 \text { i } 0 \leq w_{q} \leq 1, \text { dla wszystkich } q=1, \ldots, Q \text { i } c=1, \ldots, M
\end{gathered}
$$

gdzie:

$C I_{r}$ - wartość wskaźnika złożonego dla $r$-tego obiektu (wydziału),

$w_{q}$ - waga $q$-tego wskaźnika cząstkowego,

$I_{q r}$ - wartość znormalizowana $q$-tego wskaźnika cząstkowego dla $r$-tego obiektu,

${ }^{2}$ Dobór wskaźników cząstkowych wynikał przede wszystkim z dostępności danych i doświadczeń autora z poprzednich badań. 
dla: $r=1, \ldots, R-R$ to liczba obiektów wydziałów uwzględnionych w analizie, oraz $q=1, \ldots, Q-Q$ to liczba wskaźników cząstkowych.

W niniejszym opracowaniu do obliczenia wskaźnika złożonego zastosowano jednakowe wartości wag dla wszystkich wskaźników cząstkowych, co jest jedną z częściej stosowanych metod agregacji, zwłaszcza w przypadku działalności szkół wyższych [Paruolo i in. 2013, Szuwarzyński i Julkowski 2014].

\section{WYNIKI BADAŃ}

W tabeli 2 przedstawiono syntetyczną charakterystykę wydziałów w przekroju trzech wskaźników cząstkowych. Wartości wskaźników złożonych dla poszczególnych wydziałów przedstawiono w tabeli 3. Największą efektywn ością naukową odznaczał się Wydział Medycyny Weterynaryjnej (WMW), dla którego wskaźnik złożony wyniósł 0,67 . Dla pozostałych wydziałów wskaźnik ten kształtował się w przedziale od 0,08 do 0,61. Najgorszą efektywnością naukową charakteryzował się Wydział Nauk Społecznych (WNS).

TABELA 2. Minimalne i maksymalne wartości wskaźników cząstkowych uwzględnionych przy konstrukcji wskaźnika złożonego

\begin{tabular}{|l|c|c|}
\hline Wskaźnik cząstkowy & Minimum & Maksimum \\
\hline Liczba punktów za publikacje na nauczyciela akademickiego & 14,09 & 40,81 \\
\hline Liczba projektów NCN na nauczyciela akademickiego & 0,00 & 0,13 \\
\hline $\begin{array}{l}\text { Liczba nagród rektorskich za osiągnięcia naukowe na na- } \\
\text { uczyciela akademickiego }\end{array}$ & 0,01 & 0,35 \\
\hline
\end{tabular}

Źródło: Opracowanie własne na podstawie sprawozdania Rektora SGGW za 2015 rok.

Jak wynika z danych MNiSW, środki na działalność statutową dla wydziałów SGGW w 2016 roku wyniosły blisko 13,6 mln PLN. Charakterystykę wydziałów pod względem poziomu otrzymanej dotacji statutowej zawarto $w$ tabeli 4.

Wartość dotacji statutowej przypadającej na nauczyciela akademickiego została skonfrontowana z wynikami oceny efektywności naukowej wydziałów (rysunek). Współczynnik korelacji prostej Pearsona wyniósł 0,77, zatem siłę związku można określić jako dużąa ${ }^{3}$ Tym samym nie istnieją podstawy do odrzucenia hipotezy zerowej. Na poziomie istotności $\alpha=0,05$ wykazano statystycznie istot-

\footnotetext{
${ }^{3}$ Warto nadmienić, że również w przypadku wskaźników cząstkowych $I_{1}$ (liczba punktów za publikacje na nauczyciela akademickiego) oraz $I_{2}$ (liczba projektów NCN na nauczyciela akademickiego) siłę związku można określić jako umiarkowaną i dużą. Współczynniki korelacji prostej Pearsona wynosiły odpowiednio 0,61 oraz 0,83 . Jedynie w przypadku wskaźnika cząstkowego $I_{3}$ siła związku była słaba.
} 
ną zależność między wielkością dotacji statutowej w przeliczeniu na nauczyciela akademickiego a efektywnością naukową wydziałów (wyliczoną na podstawie wskaźnika złożonego) SGGW.

TABELA 3. Ranking wydziałów SGGW - metoda wskaźników złożonych

\begin{tabular}{|c|c|c|c|c|c|}
\hline \multirow{2}{*}{$\begin{array}{l}\text { Kod } \\
\text { wydziału }\end{array}$} & \multicolumn{3}{|c|}{$\begin{array}{c}\text { Wartości znormalizowane wskaźników } \\
\text { cząstkowych }\end{array}$} & \multirow{2}{*}{$\begin{array}{c}\text { Wskaźnik } \\
\text { złożony } \\
\text { CI }\end{array}$} & \multirow{2}{*}{$\begin{array}{c}\text { Pozycja } \\
\text { w rankingu }\end{array}$} \\
\hline & $I_{1}$ & $I_{2}$ & $I_{3}$ & & \\
\hline WMW & 1,00 & 1,00 & 0,00 & 0,67 & 1 \\
\hline WNoZ & 0,37 & 0,46 & 1,00 & 0,61 & 2 \\
\hline WRiB & 0,40 & 1,00 & 0,40 & 0,60 & 3 \\
\hline WOBiAK & 0,34 & 0,85 & 0,59 & 0,59 & 4 \\
\hline WNE & 0,66 & 0,15 & 0,60 & 0,47 & 5 \\
\hline WNoŻ & 0,60 & 0,38 & 0,28 & 0,42 & 6 \\
\hline WTD & 0,35 & 0,31 & 0,39 & 0,35 & 7 \\
\hline WBiIŚ & 0,20 & 0,23 & 0,51 & 0,31 & 8 \\
\hline WNoŻCziK & 0,21 & 0,00 & 0,52 & 0,24 & 9 \\
\hline WIP & 0,22 & 0,00 & 0,35 & 0,19 & 10 \\
\hline WL & 0,25 & 0,08 & 0,03 & 0,12 & 11 \\
\hline WZIiM & 0,03 & 0,08 & 0,16 & 0,09 & 12 \\
\hline WNS & 0,00 & 0,00 & 0,24 & 0,08 & 13 \\
\hline
\end{tabular}

Źródło: Opracowanie własne na podstawie sprawozdania Rektora SGGW za 2015 rok.

TABELA 4. Charakterystyka wydziałów SGGW pod względem poziomu otrzymanej dotacji na działalność statutową (tys. PLN)

\begin{tabular}{|l|c|c|c|c|c|}
\hline $\begin{array}{l}\text { Kod } \\
\text { wydziału }\end{array}$ & BST & DSM & SPUB & $\begin{array}{c}\text { tączna wartość } \\
\text { dotacji statutowej }\end{array}$ & $\begin{array}{c}\text { Dotacja statutowa } \\
\text { w przeliczeniu na nauczyciela } \\
\text { akademickiego }\end{array}$ \\
\hline WRiB & 1211 & 169 & 701 & 2081 & 24 \\
\hline WMW & 2106 & 271 & 270 & 2647 & 19 \\
\hline WNoZ & 883 & 190 & 0 & 1073 & 14 \\
\hline WL & 567 & 59 & 366 & 992 & 10 \\
\hline WBiÍ́ & 1207 & 137 & 120 & 1464 & 12 \\
\hline WNoŻ & 815 & 171 & 0 & 986 & 18 \\
\hline WOBiAK & 868 & 97 & 0 & 965 & 13 \\
\hline WNE & 973 & 137 & 0 & 1110 & 5 \\
\hline WTD & 436 & 61 & 0 & 497 & 7 \\
\hline WZIiM & 658 & 3 & 0 & 661 & 5 \\
\hline WIP & 382 & 58 & 0 & 440 & 6 \\
\hline WNS & 222 & 0 & 0 & 222 & 5 \\
\hline WNoŻCziK & 410 & 34 & 0 & 444 & \\
\hline
\end{tabular}

Źródło: Opracowanie własne na podstawie komunikatów MNiSW z 2016 r. dotyczących dotacji ze środków finansowych na naukę. 


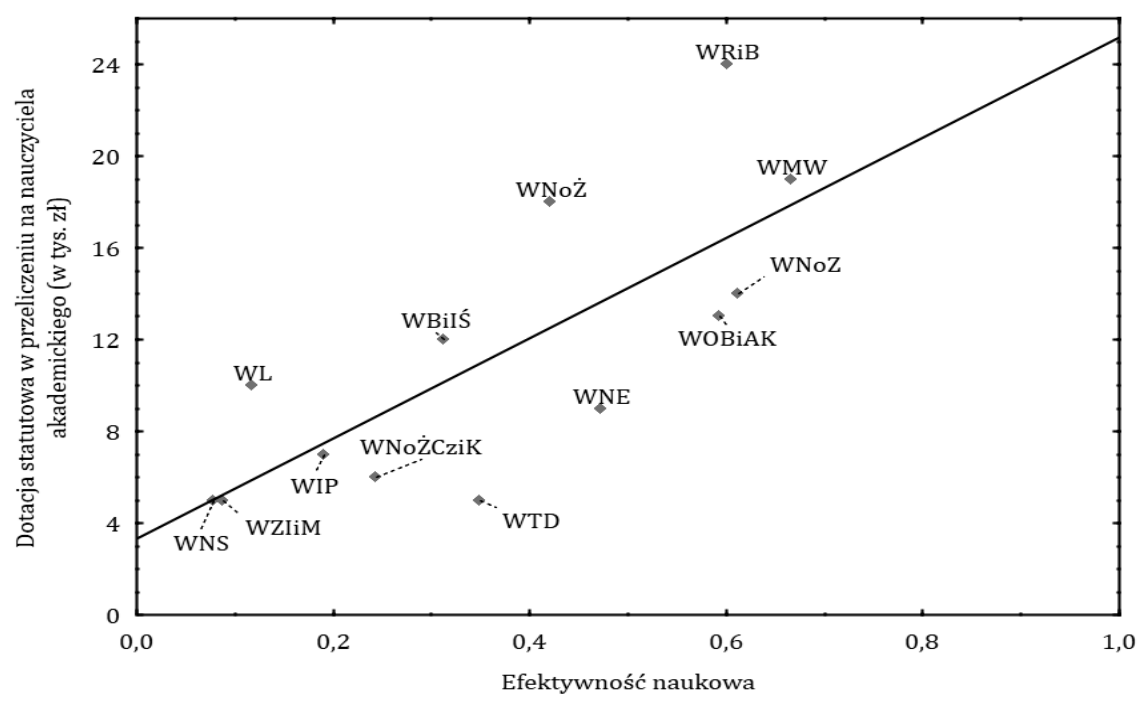

RYSUNEK 1. Wykres rozrzutu wielkości dotacji statutowej względem efektywności naukowej wydziałów SGGW

Źródło: Opracowanie własne.

\section{WNIOSKI}

Obserwowana w wielu krajach europejskich tendencja do wzrostu stosowania mechanizmów efektywnościowych w finansowaniu publicznych szkół wyższych musi być traktowana jako naturalna i nieunikniona. Wynika to z konieczności większej dyscypliny finansów publicznych, a także zapewnienia większej efektywności uczelni w zakresie kształcenia i działalności naukowo-badawczej. Ta tendencja jest również wyraźnie widoczna w Polsce. Od 2015 roku podstawowym kryterium ustalania wielkości dotacji statutowej w naszym kraju stała się kategoria naukowa, która odzwierciedla potencjał wydziałów i efekty prowadzonych przez nie badań.

W niniejszym opracowaniu autor podjął się próby określenia korelacji między wielkością dotacji statutowej a efektywnością naukową wydziałów SGGW. Przeprowadzone badania nie dały podstaw do odrzucenia hipotezy zerowej. Na poziomie istotności $\alpha=0,05$ wykazano statystycznie istotną zależność między wielkością dotacji statutowej w przeliczeniu na nauczyciela akademickiego a efektywnością naukową wydziałów.

Należy oczywiście pamiętać o ograniczeniach przeprowadzonych badań, jak i przyjętej metodyki. Po pierwsze, analiza dotyczyła wyłącznie jednej uczelni i zaledwie 13 wydziałów - bazuje zatem na skromnym zakresie materiału badaw- 
czego. Po drugie, za dyskusyjny można uznać zestaw wskaźników cząstkowych uwzględnionych przy konstrukcji wskaźnika złożonego. Przyjęte podejście wynikało z ograniczonego dostępu do danych $\mathrm{w}$ zakresie potencjalnych nakładów i efektów. W sprawozdaniu Rektora SGGW brakowało informacji m.in. o liczbie cytowań (miara jakości dorobku publikacyjnego).

Zagadnienie performance-based funding jest niezwykle interesującym i obszernym zagadnieniem badawczym. Niniejsze opracowanie nie wyczerpuje w pełni tej problematyki. Zdaniem autora przeprowadzone $\mathrm{w}$ artykule rozważania - zarówno w warstwie teoretycznej, jak i empirycznej - mogą stanowić zaczątek do dalszych prac z tego zakresu.

\section{Spis literatury}

BRESCHI S., LISSONI F., MONTOBBIO F. 2007: The scientific productivity of academic inventors: New evidence from Italian data, Economics of Innovation and New Technology 16, 101-118.

FIEDOR B. 2015: Publiczne finansowanie szkolnictwa wyższego w Europie - zmieniające się mechanizmy i modele [w:] J. Wilkin (red.), Program rozwoju szkolnictwa wyższego do 2020 r. Część IV. Finansowanie szkół wyższych ze środków publicznych, Wydawnictwo SGGW, Warszawa, 17-40.

GUILFORD J.P. 1956: Fundamental statistics in psychology and education, McGraw-Hill, New York.

GUS 2016: Szkoły wyższe i ich finanse, 2001-2015, Warszawa.

KAIKKONEN D. 2016: Shifting from Enrollment - to Performance-Based Funding in Higher Education: What Can We Learn from Washington's Experience?, Education Finance and Policy 11, 482-498.

KAMERSCHEN D.R., McKENZIE R.B., NARDINELLI C. 1991: Ekonomia, Wydawnictwo Fundacja Gospodarcza NSZZ „Solidarność”, Gdańsk.

Komisja Europejska 2009: Zarządzanie szkolnictwem wyższym w Europie. Strategie, struktury, finansowanie i kadra akademicka, Wydawnictwo Fundacji Rozwoju Systemu Edukacji, Warszawa.

Komunikat Ministra Nauki i Szkolnictwa Wyższego z dnia 14 stycznia 2016 r. o przyznanych dotacjach ze środków finansowych na naukę na finansowanie utrzymania specjalnych urządzeń badawczych, Ministerstwo Nauki i Szkolnictwa Wyższego, Warszawa 2016.

Komunikat Ministra Nauki i Szkolnictwa Wyższego z dnia 14 czerwca 2016 r. o przyznanych dotacjach ze środków finansowych na naukę na finansowanie działalności polegającej na prowadzeniu badań naukowych lub prac rozwojowych oraz zadań z nimi związanych, służących rozwojowi młodych naukowców oraz uczestników studiów doktoranckich, Ministerstwo Nauki i Szkolnictwa Wyższego, Warszawa 2016. 
Komunikat Ministra Nauki i Szkolnictwa Wyższego z dnia 2 września 2016 r. o przyznanych dotacjach ze środków finansowych na naukę na finansowanie utrzymania potencjału badawczego, Ministerstwo Nauki i Szkolnictwa Wyższego, Warszawa 2016.

KUKUŁA K. 2012: Propozycja budowy rankingu obiektów z wykorzystaniem cech ilościowych oraz jakościowych, Metody Ilościowe w Badaniach Ekonomicznych, 13, 5-16.

LOCHNER L., MORETTI E. 2004: The Effect of Education on Crime: Evidence from Prison Inmates, Arrests, and Self-Reports, American Economic Review 94, 155-189.

McMAHON W.W. 2002: Education and Development. Measuring the Social Benefits, Oxford University Press, Oxford.

MAJEWSKA K. 2015: Skąd się biorą pieniądze na uczelni? Część II. Finansowanie badań z dotacji statutowej, Pismo Uczelni „UW” 72, 8-11.

MENDOZA R.L. 2011: Fluoride-Treated Water and the Problem of Merit Goods, Water Policy, 38-52.

MURIAS P., De MIGUEL J.C., ROGRIGUEZ D., 2008: A Composite Indicator for University Quality Assessment: The Case of Spanish Higher Education System, Social Indicators Research 89, 129-146.

MUSGRAVE R.A. 1987: Merit Goods [w:] J. Eatwell, M. Milgate, P. Newman (red.), The New Palgrave: A Dictionary of Economic, Wyd. I, Palgrave MacMillan, London, 452-453.

OECD 2008: Handbook on Constructing Composite Indicators. Methodology and User Guide, OECD Publishing, Paris.

PARUOLO P., SAISANA M., SALTELLI A.: Ratings and rankings: voodoo or science?, Journal of the Royal Statistical Society. Series A, Statistical in Society, 176, 609-634.

Sprawozdanie Rektora SGGW prof. dr hab. Alojzego Szymańskiego z działalności Uczelni za 2015 rok, Wydawnictwo SGGW, Warszawa 2016.

SZUWARZYŃSKI A., JULKOWSKI B. 2014: Wykorzystanie wskaźników złożonych i metod nieparametrycznych do oceny i poprawy efektywności funkcjonowania wyższych uczelni technicznych, Edukacja 128, 54-74.

WILKIN J. 2009: Ekonomiczno-finansowe uwarunkowania rozwoju szkolnictwa wyższego w Polsce [w:] Z. Morawski (red.), Polskie szkolnictwo wyższe: stan, uwarunkowania i perspektywy, Wydawnictwo Uniwersytetu Warszawskiego, Warszawa, 79-132.

\section{THE AMOUNT OF STATUTORY GRANT AND SCIENTIFIC EFFICIENCY OF WARSAW UNIVERSITY OF LIFE SCIENCES' FACULTIES}

Abstract. Both in Poland and in other European Union countries, universities are primarily financed from public funds. This is due to the role that societies assign the spread of higher education. However, increasingly important in determining the level of public funds play performance indicators. Thus, the starting point in 
designing procedures for allocation is the postulate that more efficient units (faculties) should get much more funds than to less efficient. The hypothesis of the research assumes that there is a high positive correlation between the amount of the statutory grant and scientific efficiency of Warsaw University of Life Sciences' faculties.

Key words: public finance, statutory grant, scientific efficiency, composite indicators 